\title{
Completion Fluid dengan Nitrat - Formate Base
}

\author{
Mohammad Mahlil Nasution \\ Program Studi Teknik Perminyakan, Universitas Bhayangkara Jakarta raya \\ mahlil.nasution@dsn.ubharajaya.ac.id
}

\begin{abstract}
Abstrak
Completion Fluid adalah suatu fluida yang merupakan campuran larutan garam (Brine) yang dilarutkan kedalam air, digunakan pada saat proses penyelesaian sumur, juga untuk mematikan sumur saat dilakukannya kerja ulang sumur atau perbaikan sumur dan saat pengangkatan material yang terjatuh kedalam sumur (Fishing Job) dan juga berfungsi sebagai Packer Fluid. Completion Fluid ini umumnya digunakan pada formasi yang sensitive terhadap Shales, Clay dan mineral mineral lainnya. Tujuan dari penggunaan Completion Fluid ini adalah menghindari atau mengurangi kerusakan formasi (formation Demage). Formation damage menyebabkan lokasi yang memiliki potensi hidrokarbon besar, setelah dibor dan diproduksi aliran minyaknya menjadi kecil bahkan sulit mengalir. Formation damage perlu mendapat perhatian yang sangat serius agar produksi minyak bumi di tanah air dapat meningkat secara signifikan, karena dampaknya adalah produksi tidak meningkat secara signifikan, harga produksi minyak menjadi tinggi. Kalau upaya memperkecil kerusakan formasi dilakukan secara optimal maka diharapkan produksi akan meningkat sacara signifikan sehingga target produksi dari tahun ke tahun dapat tercapai. Penemuan ini berhubungan dengan metode pembuatan fluida komplesi untuk pengerjaan pemboran sumur baru, kegiatan kerja ulang sumur, perbaikan sumur dan aktivitas pemboran lainnya seperti yang telah dijelaskan diatas dengan menggunakan fresh water sebagai bahan dasarnya dan material solid, khususnya solid yang tingkat kelarutannya di air tinggi sekali, dalam hal ini, bahan dasar material solid yang digunakan untuk Completion fluid ini adalah Nitrat dan Alkali Formate. Completion fluid ini dapat mencapai SG (Specific Gravity) sampai dengan 2.0. Completion fluid ini memiliki kadar korosivitas (Corrosivity) yang sangat rendah, stabil pada temperatur dan tekanan yang sangat tinggi,
\end{abstract}

Kata Kunci : Completion Fluid, Brine, Fishing Job, Formation Damage, Specific Gravity, Corrosivity.

\begin{abstract}
Completion Fluid is a Liquid of Salt Solution (Brine), used during the Well Completion, also to Killing Well job, when doing Work Over Wells and Well Services Jobs and Fishing Job and also functions as Packer Fluid. Completion Fluid is generally used in Reservoir formations that are sensitive to Shales, Clay or other minerals. The purpose of using Completion Fluid is to avoid or reduce formation demage. The formation damage causes reservoir formation that has hydrocarbon potential, after being drilled and produced the flow of oil becomes small and even difficult to flow. Formation damage need to be given very serious attention so that the Oil production in our country can increase significantly because the impact is that production does not increase significantly, Cost of production is high. If an effort to minimize damage is done optimally, it is expected that production will increase significantly so that the production target from year to year can be achieved. This invention relates to the method of making Completion Fluid for Drilling, Work Over and Well Services as Drilling activities in the Oil and Gas industry, using fresh water and solids as the material, more specifically is a solid which is a soluble solid as a base formula for making the fluid. In this case, the basic material of the solid material used for completion fluid is Nitrate and Alkali Formate. This completion fluid can reach SG (Specific Gravity) up to 2.0. This completion fluid has very low corrosivity (Corrosivity), which is stable at very high temperatures and high pressures.
\end{abstract}

Keywords: Completion Fluid, Brine, Fishing Job, Formation Damage, Specific Gravity, Corrosivity. 


\section{PENDAHULUAN}

Pada tahun 2011 Pemerintah telah mentargetkan produksi minyak dalam APBN adalah 1 (Satu) Juta bph, namun lifting minyak periode januari hingga maret 2011 hanya mencapai 873 ribu bph. Upaya pengeboran eksplorasi, produksi dan perawatan sumur minyak bumi serta EOR telah dilakukan secara maksimal dari tahun 2011 hingga akhir 2014 yaitu ketika harga minyak masih baik diatas USD 80/barrel, namun produksi migas belum pernah menembus angka 900 ribu bph. Ketika target produksi tidak tercapai maka yang selalu dijadikan penyebab adalah decline yaitu penurunan kemampuan produksi minyak akibat factor alam dimana terjadi penurunan tekanan aliran minyak dari reservoir[3].

Sejak awal dilakukan pengeboran migas di tanah air terjadi penyimpangan engineering yaitu penyimpangan yang menyebabkan formation damage, dimana penanganan drilling dan completion fluid termasuk penanganan loss sirkulasi selama kegiatan pengeboran, komplesi dan perawatan sumur yaitu terjadinya pengrusakan permeability oleh solid terhadap zona reservoir migas atau disebut formation damage, sebagai penyebab utama penurunan kapasitas produksi migas [1][8][10]. Penyimpangan engineering telah menjadi kebiasaan sejak puluhan tahun yang lalu yang turun temurun hingga saat ini, hal ini bukan karena ketidak mampuan SDM di Indonesia, tetapi belum ada upaya merubah kebiasaan tersebut karena SDM Indonesia sangat ahli melakukan pengeboran dan produksi migas yaitu diakui dalam dunia internasional[2]. Secara umum dapat dikatakan bahwa produksi minyak dapat mengalir maksimal bila invasi solid kedalam zona reservoir dapat diminimize, karena semakin kecil invasi solid (pengurangan porositas), semakin besar produksi migas yang dihasilkan, sehingga penanganan drilling dan completion fluid adalah kunci utama keberhasilan peningkatan produksi migas. Invasi solid yang terjadi ketika awal-awal pengeboran pengaruhnya tidak signifikan karena tekanan reservoir masih tinggi sehingga masih mampu mendorong solid keluar. Dengan berjalannnya waktu dan meningkatnya kegiatan pengeboran maka tekanan reservoir telah mengalami penurunan tekanan secara signifikan sehingga pengaruh invasi solid saat ini ke zona reservoir akan sangat berpengaruh terhadap kapasitas produksi migas [4][9][11].

Formation damage menyebabkan lokasi yang memiliki potensi hidrokarbon besar, setelah dibor dan diproduksi aliran minyaknya menjadi kecil bahkan sulit mengalir. Formation damage perlu mendapat perhatian yang sangat serius agar produksi minyak bumi di tanah air dapat meningkat secara signifikan, karena dampaknya adalah produksi tidak meningkat secara signifikan, Harga Pokok Penjualan produksi minyak menjadi tinggi. Kalau upaya meminimize damage dilakukan secara optimal maka diharapkan produksi akan meningkat sacara signifikan sehingga target produksi dari tahun ke tahun dapat tercapai dengan upaya peningkatan pengeboran sumur eksplorasi, produksi dan EOR seperti yang telah dilakukan dalam periode sebelum tahun 2015.

Completion fluid yang digunakan selama ini dan hingga saat ini memiliki kandungan solid yang sangat tinggi yaitu lebih $300 \mathrm{NTU}$ bahkan mencapai lebih $1.000 \mathrm{NTU}$ yang berpotensi menurunkan kemampuan produksi reservoir migas dan terjadinya masalah teknis yaitu putusnya tubing pada saat akan dilakukan perawatan sumur akibat alat mekanis packer macet yang diperkirakan akibat endapan solid yang terjadi diatas packer. Secara keilmuan persyaratan pemakaian completion fluid adalah maksimal 50 NTU dan Pertamina EP juga menpersyaratkan maksimal 50 NTU hanya saja hingga saat ini belum ada supply completion fluid yang memenuhi persyaratan teknis yang ditetapkan Pertamina EP tersebut yang disupply vendor yang biasa mensupply completion fluid. Pertamina EP tidak dapat melakukan hal yang optimal tanpa dukungan mitra kerjanya. Saya telah melakukan Research and Development untuk melakukan inovasi-inovasi baru untuk mendukung peningkatan produksi di tanah air. Saya telah menemukan completion fluid yang sesuai dengan spesifikasi teknis yang diinginkan Pertamina EP dengan merek CBC Fluid (Clear 
Brine Completion Fluid) yaitu salah satunya tingkat kandungan solid $<50$ NTU. Produk completion fluid CBC Fluid (Clear Brine Completion Fluid) sudah pernah dipresentasikan di Pertamina EP Asset 5 pada tanggal 09 Februari 2018 , di kantor Pertamina EP Asset 5 Balik Papan.

Dengan pemakaian CBC Fluid ini, maka diharapkan dapat mendukung upaya peningkatan produksi migas dan efisiensi dalam operasi pengeboran dan perawatan sumur migas di tanah air[12].

\section{METODE PENELITIAN}

\section{Real Production}

Real Production adalah produksi yang dihasilkan dari suatu kegiatan pengeboran dan besarnya sangat tergantung dari Natural Production Capacity Resevoir dan pengurangan kemampuan produksi reservoir akibat formation damage selama drilling, completion dan work over. Dengan kata lain penurunan kemampuan produksi terjadi akibat akumulasi dari penurunan kapasitas produksi reservoir akibat formation damage selama drilling, completion dan work over [5].

Secara matematik dapat dirumuskan sebagai berikut ini :

$$
\mathrm{RP}=\mathrm{NPCR}-(\mathrm{DRPC}+\mathrm{CRPC}+\mathrm{WORPC})
$$

Dimana :

$\mathrm{RP}=$ Real Production, bpd

NPCR = Natural Production Capacity of Reservoir, bpd

DRPC = Drilling Reduce Production Capacity of Reservoir, bpd

$\mathrm{CRPC}=$ Completion Reduce Production Capacity of Reservoir, bpd

WORPC = Work Over Reduce Production Capacity of Reservoir, bpd

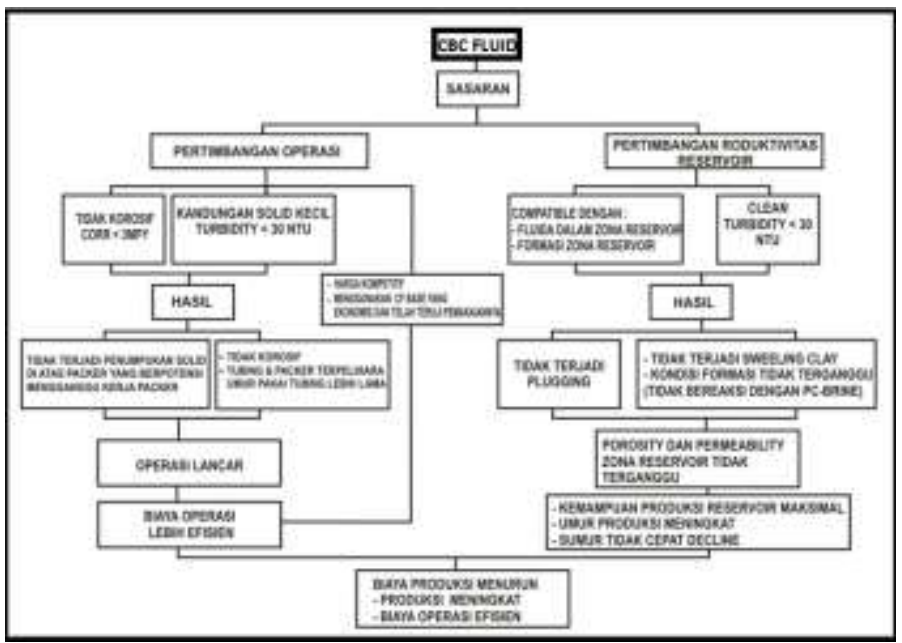

Gambar 1. Alur Proses 


\section{HASIL DAN PEMBAHASAN}

Dalam penelitian ini, kami memfokuskan pada spek yang sesuai dengan permintaan klien kami yaitu, Completion Fluid yang dapat berfungsi sebagai Killing Fluid dengan SG (Spesific Gravity) 1.7, hal ini sesuai dengan kebutuhan lapangan yang klien yang sedang berkordinasi dengan team kami. Adapun pekerjaan di lapangan tersebut adalah untuk proses fishing job. Untuk pekerjaan tersebut, sumur harus di killing (dimatikan) untuk sementara, sehingga mereka membutuhkan killing Fluid yang spesifikasinya sesuai dengan formasi sumur minyak yang mereka miliki tersebut.

Dalam penelitian ini, kami menggunakan suatu badan hukum yang berbentuk Perseroan dengan nama perusahaan PT. Emily Petroleum Indonesia.

Setelah mendapat sampel air formasi dari klien kami, maka kami segera membuat formula Completion Fluid tersebut. Adapun persyaratan yang diminta oleh klien kami dalam menanggulangi sumur minyaknya yaitu, SG sebesar 1.7, Kandungan solidnya tidak boleh lebih besar dari 50 NTU, Tidak boleh menggunakan Bromide dan Phospat yang dapat merusak formasi sumur minyak mereka.

Setelah melakukan beberapa kali percobaan dan akhirnya kami mebuat suatu formula completion yang dapat berfungsi sebagai Killing Fluid dengan bahan dasar Nitrat. Awalnya kita mengalami sedikit kesulitan karena sebagaimana kita ketahui bahwa nitrat adalah senyawa yang korosif. Oleh karena itu kami menambahkan formula aditif hasil percobaan kami kedalam completion fluid tersebut. Dan Kemudian melakukan pengetesan di lembaga Labroratorium resmi di Indonesia yaitu LEMIGAS. Dan hasil dari LEMIGAS menunjukkan seuatu yang sangat positif. Semua permintaan klien bisa kami penuhi dengan Completion fluid tersebut, seperti yang dapat dilihat dalam laporan hasil pemeriksaan lab di LEMIGAS berikut ini[6]. Komplesi Fluid ini kami beri nama dengan CBC Fluid (Clear Brine Completion Fluid)[7].

\begin{tabular}{|c|c|c|c|c|}
\hline Identitas & Penetapan & Hasil & Satuan & Metode \\
\hline Air Formasi LSE 1068 & Phospate & NIL & $\mathrm{Mg} / \mathrm{L}$ & Spektrofotometri \\
\hline Air Formasi LSE 1072 & Phosphate & NIL & $\mathrm{Mg} / \mathrm{L}$ & Spektrofotometri \\
\hline \multirow{3}{*}{ PC Brine 0107 } & Phosphate & NIL & $\mathrm{Mg} / \mathrm{L}$ & Spektrofotometri \\
\cline { 2 - 6 } & Bromide & NIL & $\mathrm{Mg} / \mathrm{L}$ & Spektrofotometri \\
\cline { 2 - 6 } & Nitrate & 848000 & $\mathrm{Mg} / \mathrm{L}$ & Spektroquant Pharo 300 \\
\hline Air Formasi LSE 1068 & Turbidity & 231.5 & $\mathrm{NTU}$ & Fotometri SQ118 \\
\hline Air Formasi LSE 1072 & Turbidity & 63 & NTU & Fotometri SQ118 \\
\hline \multirow{2}{*}{$\begin{array}{c}\text { PC Brine 0107 } \\
\text { Gravity }\end{array}$} & 1.7354 & - & Hydrometer \\
\hline $\begin{array}{c}\text { Pencampuran CBC } \\
\text { Brine + LSE 1068 } \\
\text { (50:50) }\end{array}$ & Turbidity & 8 & NTU & Fotometri SQ118 \\
\cline { 2 - 6 } & Compatibilty & 147 & NTU & Fotometri SQ118 \\
\hline $\begin{array}{c}\text { Pencampuran CBC } \\
\text { Brine + LSE 1072 } \\
\text { (50:50) }\end{array}$ & Turbidity & 32 & NTU & Fotometri SQ118 \\
\cline { 2 - 6 } & Compatibilty & \multicolumn{4}{|c|}{ Compatible } \\
\hline
\end{tabular}

Tabel 1. HASIL PENGUJIAN 


\section{KESIMPULAN}

Dari Hasil yang didapatkan dari LEMIGAS, jelas terbaca bahwa kandungan solid yang didapat dari pencampuran Completion Fluid dengan Air Formasi dari sumur klien kami di dapatkan nilai Turbidity nya sebesar 32 .

SG yang diperoleh untuk Completion Fluid ini adalah sebesar 1,7354. Dengan kandungan Phospat dan Bromide sebesar 0 (Nol).

Keuntungan penggunaan Completion Fluid yang kami beri nama CBC Fluid (Clear Brine Completion Fluid) dapat terbaca dari table diagram di sebelah ini.

Untuk meningkatkan produksi migas di tanah air maka perlu dilakukan berikut ini :

1. Gunakan drilling fluid (mud) non Barit dan Bentonite.

2. Gunakan solid control yang baik pada kegiatan pengeboran.

3. Ketika terjadi loss di zona produksi gunakan LCM acidizing dan atasi loss terlebih dahulu sebelum melanjutkan pengeboran di zona produksi untuk meminimize mud masuk ke zona reservoir

4. Gunakan solid control yang efektif

5. Mixing atau melarutkan garam $\mathrm{NaCl}, \mathrm{KCl}$ dan $\mathrm{CaCl}$ di tanki Mud di hentikan dan diganti dengan clear brine $\leq 50$ NTU yang ramah reservoir.

6. Gunakan viscosifier untuk membersihkan debris dan kotoran solid lainnya dalam sumur pada kegiatan work over.

7. Point 3 dan 4 merupakan kebiasaan sejak dimulai pengeboran di tanah air dan berlanjut hingga saat ini dan perlu diperbaiki. Tekanan reservoir di awal pengeboran masih sangat tinggi sehingga masih mampu mendorong solid keluar sedangkan saat ini sudah mengalami penurunan yang signifikan sehingga adanya invasi solid sangat berpengaruh terhadap produktifitas migas di tanah air

\section{SARAN}

Permasalahan tersebut diatas adalah suatu hal yang sangat sederhana dan sangat difahami oleh user di lapangan tetapi bila tidak dilakukan perbaikan dampaknya terhadap produksi migas sangat besar, karena selama ini ketika target produksi tidak tercapai selalu yang dijadikan alas an adalah disebabkan penurunan tekanan reservoir yang menyebabkan decline nya produksi . Untuk itu disarankan

1. Ada peraturan di Pertamina tentang pelaksanaan, pengawasan dan evaluasi pengeboran, completion dan work over yang jelas dan tegas agar minimal hal tersebut diatas dapat diimplementasikan di lapangan dan di awasi secara cermat serta dievaluasi untuk dapat dilakukan peningkatan operasional agar potensi hidrokarbon yang ada di tanah air dapat dimanfaatkan dan dinikmati secara optimal oleh bangsa Indonesia. Peraturan tersebut juga diharapkan memberi ruang dan landasan hukum kepada user agar bisa lebih aktif dan inovatif tanpa adanya rasa keraguan dan kekhawatiran dalam melakukan inovasi.

2. Perlu ada team pembuat peraturan atau SOP tersebut yang terdiri dari Akademisi, professional, praktisi dan dari tenaga ahli di perusahaan perminyakan ditanah air yang bertujuan agar operasi pengeboran, completion dan work over yang berorientasi mengamankan reservoir dari formation damage bukan bagaimana menyelesaikan suatu sumur secepatnya. Perlu ada team pengawas independen untuk mengimplementasikan hal hal tersebut diatas. 


\section{DAFTAR PUSTAKA}

[1] H. C. . D. and G. R. Gray and T. . J. Wright, Composion And Properties Of Drilling And Complition Fluids. Guide to Drilling, Work Over and Completion Fluid, World Oil, 1978.

[2] F. Khodja, M., Khodja-Saber, M., Canselier, J. P., Cohaut, N. and Bergaya, "Drilling fluid technology: performances and environmental considerations," Prod. Serv. From R\&D to Final Solut., pp. 227-232, 2010.

[3] H. S. K. R. Indonesia, “Target 2019 2,02 Juta BOEPD, Pemerintah Ungkap Strategi Penuhi Kebutuhan Migas Nasional,” 2019.

[4] Rudi Rubiandini RS, Buku Teknik Pemboran Volume 1, Ke 4. Bandung: ITB, 2014.

[5] E. . Baars, D.L., Watney W. L., Steeples, D.W., and Brostuen, "Petroleum: a primer for Kansas," Pet. a Prim. Kansas, no. Kansas, 2014.

[6] W. Fluids, "Oil \& Gas.”

[7] J.T. Patton (New Mexico State U.) ; P.F. Phelan (Los Alamos Natl Laboratory), Well Damage Hazards Associated With Conventional Completion Fluids. New Mexico, 2012.

[8] Hernowo Widodo, Rehab Laila, Pengaruh Monosodium Glutamat Sebagai Inhibitor Terhadap Kecepatan Korosi dan Karakteristik Mikrostruktur pada Baja AISI 1045 Dengan Media Asam Sitrat dan Kalium Hidroksida. Jurnal Penelitian dan Karya Ilmiah Lemlit Vol 2 No.2 2017.

[9] Meikrismahariyanto, Bungaran Saing, Hernowo Widodo, Concentration Effect of Sodium Carbonate and Sodium Aluminate as Accelerator and $\mathrm{H}_{2} \mathrm{O}$ Mixing against Physical Properties: Flow Ability, Setting Time, and Strength in Low Cement Castable Refractory Product ( Cas Study : PT. Indoporlen ), AIP Conference Prosiding 1877, 090002 ( 2017 ), Langkawi, Malaysia.

[10] Hernowo Widodo, Lisa Adhani , Elvi Kustiyah, Ilham Santoso, Studi Pengaruh Jenis Katalis, Waktu Reaksi dan Penurunan Bilangan Iodine pada Pembuatan Cocoa Butter Substitute dengan Proses Hidrogenasi Minyak Kelapa. Jurnal Jaring Saintek Volume 1 No. 12019.

[11] Aly Rasyid, Tyastuti Sri Lestari, Penentuan Produktivitas Zona Minyak dengan Menggunakan Modular Formation Dynamic Thechnology. Jurnal Kajian Ilmiah Volume 18 No.1 2018

[12] Hernowo Widodo, Elvi Kustiyah, Yustinus Trihusodo, Amaliah Annisa, Studi Penentuan Umur Simpan Minyak Sawit dengan Metode Accelerated Shelf Lifetesting. Barometer Volume 4 No. 22019. 